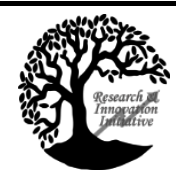

\title{
Food Choices and COVID-19: A Study of Traditional Dietary Habits in Chandigarh, India
}

\section{Suraj Das ${ }^{1^{*}}$ Dr. Anindya Jayanta Mishra²}

${ }^{1}$ Senior Research Fellow (SRF), Department of Humanities and Social Sciences, Indian Institute of Technology Roorkee, Uttarakhand, India

${ }^{2}$ Professor, Department of Humanities and Social Sciences, Indian Institute of Technology Roorkee, Uttarakhand, India *Corresponding author: sdas@hs.iitr.ac.in https://riiopenjournals.com/index.php/society sustainability/index

Doi: https://doi.org/10.38157/society_sustainability.v3i1.244

Citation: Das, S. \& Mishra, A.J. (2021). Food Choices and COVID-19: A Study of Traditional Dietary Habits in Chandigarh, India, Society \& Sustainability, 3(1), 18-25. Doi: https://doi.org/10.38157/society_sustainability.v3i1.244

\section{Research Note}

\begin{abstract}
The study aims to understand the traditional dietary habits during the COVID-19 pandemic and to comprehend the role of societal norms associated with gender in the context of Chandigarh, India. The present paper reports the findings from a cross-section survey conducted in September-October 2020 in Chandigarh in India. In total, there were 70 participants for the primary survey. A five-point Likert scale was used for the primary survey on a scale anchored with Strongly Agree (5) to Strongly Disagree (1). We conducted a Chi-square test and Regression Analysis to test the hypothesis. The result proved that sociocultural and gender norms are significant for food choice during pandemics. The study will benefit the policymakers while framing the policy dealing with pandemic considering the local socio-cultural perspective. The sample size was very small. Therefore, the outcomes of the study may not be generalized for the whole population of Chandigarh, India.
\end{abstract}

Keywords: Food Choices, Socio-cultural norms, Gender, COVID-19, India

\section{Introduction}

Novel Corona Virus is the leading cause of the COVID-19 pandemic, which has become a severe global threat for the human race. During the early stage, in late December 2019, the patients were diagnosed with pneumonia of an unknown etiology (Bogoch et al., 2020). Initially, reports predicted that the SARS-CoV-2 is responsible for the coronavirus outbreak that leads to the COVID-19. Gradually the epidemic spread throughout the world and the World Health Organization (WHO) declared it a pandemic and called for a global health emergency (Lu et al., 2020). Due to climate change, various kinds of ecological interactions will occur because zoonotic diseases will likely evolve in new transitional environmental zones. The developed world will suffer from the re-emergence of old disease, while the third world will experience the same detrimental effect (Patz et al., 2005). As per the estimates, by 2050, the global population is 
expected to reach as much as 10 billion. Therefore, the concerns over climatic and environmental changes as well as the depletion of natural resources are growing among the policymakers (Pimentel et al., 2010).

Furthermore, the individual and the community resilience strategy have always been the firstline defense for better health approaches during health emergencies such as the COVID-19 pandemic. Therefore, the nutritional status of an individual plays a significant role against destabilization during epidemics. Good diet quality of food choice is essential not only for physical but also for mental health. The World Health Organization (WHO) has been advocating the integration of traditional knowledge in national policies and programs since 1991. Similarly, in resonance with WHO's guidance, national ministries of health are promoting the incorporation of indigenous and local knowledge as a better option to combat various diseases (Anyonge et al., 2006). Due to COVID-19, the food supply chains got disturbed. Global trade of foodstuffs was interrupted due to the fear of further acceleration of diseases across the countries. Therefore, the chances are high that the nations will strengthen institutions that govern international transactions. Most importantly, based on the COVID-19 pandemic experience, governments will try to reverse the dietary shifts in favor of their traditional and local food system (Kerr, 2020).

For effective policies and programs that not only reduce the chance of transmission of the virus but also improves human safety, a socio-cultural perspective is inevitable. Literature and research are scarce on Chandigarh's dietary habits from the socio-cultural perspective. Hence, the authors conducted the present study. Accordingly, the study's objective was to understand the traditional dietary habits during the COVID-19 pandemic and to comprehend the role of societal norms associated with gender. The current study reports the finding of a survey conducted in Chandigarh, India, assessing the individual's perception and attitude towards culturally vital food and traditional norms associated with it during the pandemic.

\section{Literature Review and Development of Hypotheses}

One of the most significant challenges in pandemic planning is to develop a holistic and integrated approach, which is resilient enough to keep functioning during public health emergencies and pandemic-like situations such as the COVID-19 pandemic. Pieces of evidence from the literature suggest that an efficient and multidimensional response is crucial for addressing the issue, and dietary habits and food choices could offer a possible solution. A very often socio-cultural element related to nutritional habits gets little attention at the policy and program formulation level. That fails the very strategies meant to resolve the issues due to the communities' trust issue (Rothan \& Byrareddy, 2020).

In response to the pandemic like HIV and AIDS, the local communities in southern African countries must rely on traditional knowledge systems. The weak health infrastructure and pervasive poverty are the most significant challenges to the local governments in administering antiretroviral therapy to the affected person. Therefore, the government and policymakers institutionalized local and traditional medicine (Anyonge et al., 2006).

In the mid-1980s, the Nuxalk Food and Nutrition Program was introduced by the local government due to changes in eating habits and nutritional status. It was the first of its kind 
program that was later followed by many similar initiatives in Canada. The plan promoted traditional food resources and increased the family's number using traditional food, mainly fish. Nutritional status got improved with the increasing uses of fruit and vegetables etc. But, in 2006, a follow-up consultation examined the long-term impact of the program. Contrary to the early days before the authority introduced the nutritional program, the concerns related to obesity and chronic disease were high. The same was the shift in traditional dietary habits due to environmental changes in Nuxalk Nation (Turnern et al., 2013).

Similarly, as observed in the Federated States of Micronesia (FSM) that neglecting traditional food systems and changes in dietary patterns and lifestyle changes leads to increased rates of noncommunicable diseases. Therefore, for the reversal of that trend, the food-based intervention was initiated in one Pohnpeian community in FSM for two years by the administration. Through the intervention, local food production and consumption were promoted through education, training, and various social initiatives with the message "Go Local." Because of these efforts by the local authority, dietary diversity and the local community's health status improved(Kaufer et al., 2010).

Also, Creed-Kanashiro et al. (2013) conducted a case study related to a project aimed to increase the health status and nutritional standards of Awajun communities of the Cenepa River in Peru through the promotion of traditional dietary habits and cultures. Since the project was based on participatory research that focuses on increasing conventional diets' usages and production, it improves accessibility through nutritious traditional food. The study observed that the local and traditional knowledge related to culturally significant food could be maintained by promoting specific traditional foods' nutritional values.

In another study by Salomeyesudas et al. (2013) in the Dalit rural communities of the Zaheerabad region of the Southern part of India, the women suffered from chronic energy deficiency for a very long time. To resolve the problem, the researchers found 329 species of plants and animals with high nutritional value, which showed a protective association against women's chronic energy deficiency. So the researchers recommended promoting traditional food fats, pulses, vegetables, etc., via ecological farming and local knowledge. Hence, after the authorities' intervention through local women farmers' organization called Sanghams in the area, the health condition got improved with the promotion of local and traditional knowledge.

Another recent study by Xie et al. (2020) measured the risk perception and attitudes towards risky foods, organic food, and game meat in younger and older generations. The study concluded that risk perception is high toward game meat but less towards organic food. Another observation was that the older generation had a more positive attitude towards organic food because of the more significant association of nutritional and medicinal value. Additionally, the study also observed that due to the COVID-19 pandemic, the attitude towards more healthy and organic food gets firmed and strong. Similarly, Gupta et al. (2017) noticed a comparable effect on males and females due to westernization; it was found that the family and the gender-associated norms were the significant elements in making a dietary choice in Chandigarh.

Thus, based on the previous literature, we developed the following two null hypotheses.

$\mathrm{H}_{01}$ : There is no significant influence of the COVID-19 pandemic on traditional food choices. 
$\mathrm{H}_{02}$ : Gender and Societal norms are not significant in the selection of food.

\section{Methodology}

The present study has used the cross-sectional descriptive survey designs that have utilized the mixed-method approach for examining the variation across the cases. Additionally, correlation analysis was done, which allows the researcher to do the research and evaluation of the relationship between the variables from the responses of the respondents (Kerr, 2020). The data were collected during September/October 2020 by researchers. Data were collected using a questionnaire. The questionnaires were divided into two sections. Section A captured the respondents' demographic information, such as age, gender, marital status, and Section B consisted of questions to be studied for the conceptual model. We measured the responses on a 5-point Likert scale (1=Strongly Disagree; 2=Disagree; 3=Neutral; 4=Agree; 5=Strongly Agree). A total of 70 respondents was surveyed for the primary data through convenience sampling in Chandigarh, India.

For data analysis, both descriptive and inferential statistics were used. The frequency and the percentages of responses were used for qualitative analysis of the open-ended questions, and regression analysis was done to find whether there is a significant influence of the COVID-19 pandemic on the relationship between cultural factors and the choice of traditional food in Chandigarh, India. Chi-square at 95\% confidence level was used to test the hypothesis and ANOVA.

\section{Results and Discussion}

The coding and analysis of data were done based on demographic factors and factors that determine food choices. Therefore the COVID-19 effect pandemic on the traditional food choices was recognized as mentioned below:

\subsection{Demographic Factors}

Personal data such as age, gender, and marital status were collected with the respondents' prior consent because of their importance in food choices and their relevance to the present study. The results observed on the participants' age were given in table 1. Among the participants, the age groups 14-28 years consist of 58 participants (82.9\%), 29-43 years were 9 participants $(12.9 \%)$, while above 44 years were three respondents $(4.29 \%)$.

Table 1: Age of the Respondents

\begin{tabular}{|llll|}
\hline Variables & Frequency & Percentage & Cumulative Frequency \\
\hline 14-28 Years & 58 & 82.86 & 58 \\
29-43 Years & 9 & 12.86 & 67 \\
Above 44 Years & 3 & 4.29 & 70 \\
\hline Total & 70 & 100.00 & \\
\hline
\end{tabular}

We presented the compositions of the participants' gender in Table 2. The participants comprised $42(60 \%)$ male and $28(40 \%)$ female. 
Table 2: Gender of the Respondents

\begin{tabular}{|llll|}
\hline Variables & Frequency & Percentage & Cumulative Frequency \\
\hline Male & 42 & 60.00 & 42 \\
Female & 28 & 40.00 & 70 \\
\hline Total & 70 & 100.00 & \\
\hline
\end{tabular}

Out of the 70 participants, 25 respondents (35.71\%) were married, and $45(64.29 \%)$ were unmarried. We showed the results in table 3.

\section{Table 3: Marital Status of Participants}

\begin{tabular}{|llll|}
\hline Variables & Frequency & Percentage & Cumulative Frequency \\
\hline Married & 25 & 35.71 & 25 \\
Unmarried & 45 & 64.29 & 70 \\
\hline Total & 70 & 100 & \\
\hline
\end{tabular}

\subsection{Hypothesis Testing}

Ho1: There is no significant influence of COVID-19 pandemic traditional food choices in Chandigarh The authors used Regression analysis to determine if there is a significant influence of the COVID19 pandemic on Chandigarh's traditional food choices. The null hypothesis was tested at a 5\% level of significance, and we presented the results in table 4 . The model summary provides the correlation coefficient and coefficient of determination $\left(R^{2}\right)$ for the regression model. The correlation coefficient $(\mathrm{R})$ of 0.156 suggests a weak positive influence of the COVID-19 pandemic on Chandigarh's traditional food choices. The result of the present study contradicts earlier studies (Anyonge et al., 2006; Creed-Kanashiro et al., 2013) that have observed that traditional food choices get influenced during the times of pandemics.

Table 4 Regression Model Summary

\begin{tabular}{|lllll|}
\hline & & $\mathbf{R}$ & Adjusted & \\
Model & $\mathbf{R}$ & Square & R Square & Std. Error of the Estimate \\
1 & $.156^{\mathrm{a}}$ & .024 & .010 & .994 \\
\hline
\end{tabular}

a. Predictors: (Constant), COVID-19 pandemic

b. Dependent variable: Traditional Food choices

Table 5. ANOVA

\begin{tabular}{|c|c|c|c|c|c|c|}
\hline \multicolumn{2}{|c|}{ Model } & \multirow{2}{*}{$\begin{array}{l}\text { Sum } \\
\text { Squares } \\
1.655\end{array}$} & \multirow{2}{*}{$\begin{array}{l}\mathbf{~ o f} \\
\mathbf{d f} \\
1\end{array}$} & \multirow{4}{*}{$\begin{array}{l}\text { Mean Square } \\
1.655 \\
.988\end{array}$} & \multirow{4}{*}{$\begin{array}{l}\text { F } \\
1.675\end{array}$} & \multirow{4}{*}{$\begin{array}{l}\text { Sig. } \\
.200^{\mathrm{b}}\end{array}$} \\
\hline \multirow[t]{3}{*}{1} & Regression & & & & & \\
\hline & Residual & 66.171 & 67 & & & \\
\hline & Total & 67.826 & 68 & & & \\
\hline \multicolumn{7}{|c|}{ a. Dependent Variable: Traditional Foods } \\
\hline \multicolumn{7}{|c|}{ b. Predictors: (Constant), COVID-19 pandemic } \\
\hline
\end{tabular}


Table 6: Coefficients ${ }^{a}$

\begin{tabular}{|c|c|c|c|c|c|}
\hline \multirow{5}{*}{\begin{tabular}{|lr} 
Model \\
$\begin{array}{ll}1 & \text { (Constant) } \\
& \text { COVID-19 } \\
& \text { pandemic }\end{array}$
\end{tabular}} & \multicolumn{2}{|c|}{$\begin{array}{l}\text { Unstandardized } \\
\text { Coefficients }\end{array}$} & \multirow[t]{2}{*}{$\begin{array}{l}\text { Standardized } \\
\text { Coefficients }\end{array}$} & \multirow{4}{*}{$\begin{array}{l}\mathbf{t} \\
7.770\end{array}$} & \multirow{4}{*}{$\begin{array}{l}\text { Sig. } \\
.000\end{array}$} \\
\hline & & Std. & & & \\
\hline & B & Error & Beta & & \\
\hline & 3.336 & .429 & & & \\
\hline & .137 & .106 & .156 & 1.294 & .200 \\
\hline
\end{tabular}

The ANOVA shows whether the regression model explains a statistically significant proportion of the variance. Specifically, it uses a ratio to compare how well the linear regression model predicts how accurate merely using the outcome data's mean as an estimate is. The model predicts the outcome from the analysis, and thus, given the weak correlation, the model is statistically not significant $(p=.2>0.05)$.

The Regression Analysis table gives the values for the regression line. The COVID-19 factors row in the Coefficient column provides the regression line's gradient, the regression coefficient. The result predicts an increase of 0.137 on traditional food choice and for every COVID-19 aspect for every cultural factor. From the analysis, the study was unable to reject the null hypothesis and concludes that at a $95 \%$ confidence level p-value was 0.2 , which is greater than .005 . Thus our null hypothesis was rejected. Hence, the study observed a significant influence of COVID-19 pandemic factors on the choice of traditional food in Chandigarh.

Ho2: Gender and Societal norms are not significant in the selection of food.

We use the Chi-square test to determine whether there is any significant difference in the relationship between gender and societal norms related to food choices. Researchers tested the null hypothesis at a 5\% level of significance. From the analysis, at a 5\%significance level of table 7, the result shows that the Pearson Chi-Square value was 0.990. Since, the p-value is 0.99) which is greater than alpha value i.e. $(p=0.99>0.05)$. Hence, the study was unable to reject the null hypothesis and concludes that at a $95 \%$ confidence level, there is no meaningful relationship between gender and Societal norms related to food choices in Chandigarh. Therefore, the present study is inconsistent with (Gupta et al., 2017; Salomeyesudas et al., 2013; Xie et al., 2020) the existing studies that have observed gender and societal norms are significant for the selection of food.

Table 7 Chi-Square Tests

\begin{tabular}{|llll|}
\hline \multicolumn{1}{|c|}{ Chi- } & Value & df & Sig. (2-sided) \\
\hline $\begin{array}{l}\text { Pearson } \\
\text { Square }\end{array}$ & 4 & .990 \\
\hline Likelihood Ratio & .295 & 4 & .990 \\
\hline $\begin{array}{l}\text { Linear-by-Linear } \\
\text { Association }\end{array}$ & .001 & 1 & .970 \\
\hline N of Valid Cases & 70 & & \\
\hline a. 3 cells (30.0\%) have an expected count of less than 5. The minimum expected count is 2.80. \\
\hline
\end{tabular}




\section{Conclusion}

The present study observed that the societal and gender norms associated with food selection play an important role in society during a pandemic. But very often, socio-cultural aspects receive little attention during policy formations that lead to poor efficacy of the policies. Therefore, the focus should be on understanding the cultural variation among the local communities and the importance of traditional belief systems associated with food habits.

Furthermore, policies are most successful when they stress the use of cultural knowledge to advance health promotion activities to improve the mental, emotional, spiritual, and physical health of the individuals and communities. The findings of the study may help decision-makers to prepare for a pandemic, considering the allocation of limited resources and responding dynamically. It may include increasing the awareness of the importance of traditional food sources, promotion of traditional food production and consumption, and increasing local people's knowledge, and skills for enhancing gender-specific food and nutrition security.

\section{Limitations and directions for future research}

Since the study is based on small sample size, the result does not present Chandigarh's whole picture. So, care should be taken in generalizing the results. However, the results can be an indication, which shows that the socio-cultural beliefs and gender-associated norms play an essential role in food choices during the pandemic. Therefore, future studies can be conducted on larger samples.

Funding: This project was funded by University Grant Commission (UGC), India. The authors therefore acknowledge with thanks the UGC for financial support.

Acknowledgement: The authors like to express their gratitude to Ms. Priya, Department of Humanities and Social Sciences, Indian Institute of Technology Roorkee, for her valuable assistance in data analysis.

Author Contributions: Suraj Das conceived the idea and collected data; Suraj Das and Dr. A.J. Mishra both analyzed the data; Suraj Das wrote the paper.

Conflict of Interest: The authors declare no conflict of interest.

\section{REFERENCES}

Anyonge, C. H., Rugalema, G., Kayambazinthu, D., Sitoe, A., \& Barany, M. (2006). Fuelwood, food, and medicine: The role of forests in the response to HIV and AIDS in rural areas of southern Africa. Unasylva, 57(2), 20.

Bogoch, I. I., Watts, A., Thomas-Bachli, A., Huber, C., Kraemer, M. U. G., \& Khan, K. (2020). Pneumonia of unknown etiology in Wuhan, China: Potential for international spread via commercial air travel. Journal of Travel Medicine, 27(2), 1-3. https://doi.org/10.1093/jtm/taaa008

Creed-Kanashiro, H., Carrasco, M., Abad, M., Tuesta, I., Kuhnlein, H., Erasmus, B., Spigelski, D., \& Burlingame, B. (2013). Promotion of traditional foods to improve the nutrition and health of the Awajún of the Cenepa River in Peru. In 'Indigenous Peoples' food systems \& well-being: Interventions \& policies for healthy communities'. Centre for Indigenous Peoples' Nutrition and Environment (CINE) and School of Dietetics and Human Nutrition, McGill University, Montreal, Quebec, Canada

Gupta, N., Bhargava, R., Chavan, B., \& Sharan, P. (2017). Eating attitudes and body shape concerns among medical 
students in Chandigarh. Indian Journal of Social Psychiatry, 33(3), 219. https://doi.org/10.4103/0971-9962.214605

Kaufer, L., Englberger, L., Cue, R., Lorens, A., Albert, K., Pedrus, P., \& Kuhnlein, H. V. (2010). Evaluation of a 0 "traditional food for health" intervention in Pohnpei, Federated States of Micronesia. Pacific Health Dialog, 16(1), 61-73.

Kerr, W. A. (2020). The COVID-19 pandemic and agriculture: Short- and long-run implications for international trade relations. Canadian Journal of Agricultural Economics, 68(2), 225-229. https://doi.org/10.1111/cjag.12230

Lu, H., Stratton, C. W., \& Tang, Y. W. (2020). Outbreak of pneumonia of unknown etiology in Wuhan, China: The mystery and the miracle. Journal of Medical Virology, 92(4), 401-402. https://doi.org/10.1002/jmv.25678

Patz, J. A., Campbell-Lendrum, D., Holloway, T., \& Foley, J. A. (2005). Impact of regional climate change on human health. Nature, 438(7066), 310-317. https://doi.org/10.1038/nature04188

Pimentel, D., Whitecraft, M., Scott, Z. R., Zhao, L., Satkiewicz, P., Scott, T. J., Phillips, J., Szimak, D., Singh, G., Gonzalez, D. O., \& Moe, T. L. (2010). Will Limited Land, Water, and Energy Control Human Population Numbers in the Future? Human Ecology, 38(5), 599-611. https://doi.org/10.1007/s10745-010-9346-y

Rothan, H. A., \& Byrareddy, S. N. (2020). The epidemiology and pathogenesis of coronavirus disease (COVID-19) outbreak. Journal of Autoimmunity, 109, 102433. https://doi.org/10.1016/j.jaut.2020.102433

Salomeyesudas, B., Kuhnlein, H. V, Schmid, M. A., Satheesh, P. V, \& Eegeland, G. M. (2013). The Dalit food system and maternal and child nutrition in Andhra Pradesh, South India. In Indigenous Peoples' food systems \& wellbeing: Interventions \& policies for healthy communities, Centre for Indigenous Peoples' Nutrition and Environment (CINE) and School of Dietetics and Human Nutrition, McGill University, Montreal, Quebec, Canada

Turnern, N. J., Tallio, W. r., Burgess, S., \& Kuhnlein, H. V. (2013). The Nuxalk Food and Nutrition Program for Health revisited. In 'Indigenous Peoples' food systems \& well-being : Interventions \& policies for healthy communities', 177-190. Centre for Indigenous Peoples' Nutrition and Environment (CINE) and School of Dietetics and Human Nutrition, McGill University, Montreal, Quebec, Canada

Xie, X., Huang, L., Li, J., \& Zhu, H. (2020). Generational differences in perceptions of food health/risk and attitudes toward organic food and game meat: The case of the COVID-19 crisis in China. International Journal of Environmental Research and Public Health, 17(9), 3148. https://doi.org/10.3390/ijerph17093148

(C) 2021 by the authors. Licensee Research \& Innovation Initiative, Michigan, USA. This article is an open-access article distributed under the terms and conditions of the Creative Commons Attribution (CC-BY) license (http://creativecommons.org/licenses/by/4.0/). 